\title{
Creative participation in construction firms: bridging creativity and innovation
}

\author{
Natalya Sergeeva \\ University of Reading, \\ School of Construction \\ Management and Engineering, \\ Whiteknights, Reading, UK
}

\author{
Milan Radosavljevic \\ University of Reading, School of \\ Construction Management and Engineering, \\ Whiteknights, Reading, UK \\ m.radosavljevic@reading.ac.uk
}

DOI 10.5592/otmcj.2012.2.5

Research paper

\section{Keywords}

creative participation, ideas, personality, radicality, creativity, innovation creative participation, ideas, personality, radicality, creativity, innovation
AN INTRICATE EVOLUTION OF MAINSTREAM THEORIES FOLLOWS THE GROWING NEED TO EXPLAIN EMPLOYEES' COMmitMENT AND ENGAgEMENT. Our understanding of these work-related phenomena and behaviour has improved but creativity and innovation as desired indicators are still often treated as coexisting constructs with very little attention given to a state of willingness of an individual to even consider contributing ideas. In this research we investigate the influence of knowledge and understanding, perceived radicality, personality dimensions, and favouring of ideas on employee willingness to creatively participate in order to trace its existence in propagation of ideas. A total of 76 construction and non-construction professionals participated in between-subject quasi-experiments. We also proposed IPO-based radicality of ideas construct from the viewpoint of employees involved in the processes of transformation. The research findings show that experts with deep understanding of the work are more likely to contribute highly radical ideas to decision-makers than less knowledgeable employees. Furthermore, personal factors that impact employee willingness to creatively participate have been valued higher than organisational factors. Personality dimensions by The BigFive Inventory have shown no effect on willingness to contribute ideas, while favouring of ideas showed a significant effect. In general, the findings show similarities with some studies of consumer willingness to participate in co-creation processes and thus indicate that firms may be studied as dynamic internal markets of ideas. 


\section{INTRODUCTION}

Committed and highly engaged employees that are passionate about their work represent the backbone of successful companies (Bakker and Schaufeli, 2008; Ho et al., 2011). Many scholars have argued for decades that successful companies rely on entrepreneurial innovations of their teams and individual employees (Chadwick and Dabu, 2009; Hitt et al., 1997). It has also long ago been established that such employees are devoted to a task and generate more ideas or solutions to potential problems (Simon, 1955). However, a creative idea can only become an innovation or a solution to a problem if it is transformed from a concept into reality (Roffe, 1999). By providing ideas, an individual is, therefore, clearly at the crux of this transformation (Mumford, 2000). Whilst creativity in this form is recognized as an important underpinning of innovation (Oldham and Cummings, 1996; Zhou, 2003), most of the research on the subject has focused on the outcomes of creative processes (Zhou and George, 2003). Scholars that conceptualize creativity as a process are still forming an emerging field of enquiry (Gilson, 2008; Lubart, 2001). However, even in these studies the question whether an individual is willing to contribute the generated ideas before their implementation has rarely received deserved attention. In response to this gap, it is not surprising that Zhang and Bartol (2010) call for future research to focus on studying how employee involvement in the implementation phase competes with creative process engagement. One might get closer to answer the question by looking at behavioural facets of intrinsic motivation and domain-relevant skills that have been extensively studied within the arena of creativity research (Amabile, 1996; Amabile et al., 1994). These past investigations show that intrinsically motivated employees dedicated more time to task completion and were also far more committed, but it remains unclear whether they would also demonstrate greater in-task willingness to contribute creative ideas in general. Complementary studies reveal that motivational orientation can change depending on the social contexts in which individuals interact (Amabile, 1979; Lepper et al., 1973), as well as their individual differences in responding to these contextual differences (Deci and Ryan, 1985; Hirst et al., 2009). The extant literature on creativity clearly recognizes the importance of individual differences, but they focus on their impact on behaviour, and there is a dearth of scientific investigations on the individual state of willingness to creatively participate.

The above question has received some attention in studies on consumer creativity, where willingness-driven creative participation is defined as consumers' co-creation (Lan, 2007). In this particular inquiry findings show that consumers are unwilling to engage in creative participation if they perceive the creative process as unnecessary. Looking at this phenomenon from an interactionist perspective, businesses and consumers thus engage in mutually adaptive systems of actions (Anderson et al, 1998). Although contextually different, this dynamic mutuality relates back to intrinsic motivation, pointing at a possibility that even engaged and intrinsically motivated employees may not be willing to contribute ideas at some point in time if they, for one reason or another, perceive this as unnecessary or even undesirable. Perception may significantly influence an individual's willingness to creatively participate regardless of whether one is investigating a consumer or an employee. It has been suggested that in groups with diverse levels of talent and salient characteristics willingness to creatively participate may be an important mediating variable that gives strength to work groups' acceptance and shapes their subsequent cognitive processes (Milliken et al., 2003). Historically, creative personality and creative talent have been given a lot of attention (Isaksen and Puccio, 1988; MacKinnon, 1965), but surprisingly little is known about employees' willingness to creatively participate from their own individual perspective.

To address the above gaps in research on employee willingness to creatively participate, this study aims to contribute to extant literature in three ways. First, we build on previous related research to progress the conceptualization of factors that potentially affect willingness to creatively participate with either positive or negative outcomes.

Second, relating to previous research we progress the conceptualization of radicality and investigate whether different levels of radicality of generated ideas influence employees' willingness to creatively participate with more or less work-related groups of people.

Third, we investigate the relationship between knowledge and understanding, perceived radicality, personality dimensions by the Big Five Inventory (BFI), and favouring of ideas on one hand and employee willingness to creatively participate on the other, by administering between-subject quasi-experiments involving 76 participants. A more detailed overview of the research design is provided later in the text.

The above contributions are valuable because individuals often work in groups and teams where effective utilization of individual resources determines group/team success (e.g. Taggar, 2002). Furthermore, to our knowledge, this is the first study to investigate willingness to creatively participate as defined above from the viewpoint of employees who are involved in the processes of transformation.

\section{Relevant theories \\ Motivation Theories}

Interest in the interplay between work environment, personality, and employees' engagement can be traced back through various employee motivation 
theories to the early works of Taylor (1917), Maslow (1943), Weber (1947), Fayol (1949), Hertzberg (1964), Mintzberg (2004) and many others. Taylor's (1917) and Weber's (1947) immediate concern with work standardization is restricted by their mechanistic interpretation of what we now understand as a socially complex work environment, but even they recognize the need for employee engagement. Fayol (1949) is not dissimilar in highlighting the inefficiency of employee dissatisfaction and high turnover. Maslow (1943) then clearly moves away from the mechanistic view of the scientific management theorists by expressing innate interest in motivation. Maslow (1947) recognized the existence of the hierarchy of needs that are exerted differently by individuals, but his later work, and even the whole body of literature around his principles, did not profoundly address the issue of inherent willingness to contribute new ideas and is purely directed towards work motivation. Mintzberg (2004) is also less of a conformist, and believes managers are the ones who create the work atmosphere through often informal communication, but is far less clear about an individual as a dynamic source of new ideas. Hertzberg's (1964) motivators and hygiene factors come perhaps even closer by recognizing achievement, recognition, responsibility and advancement as some of the most important motivators, but again he was concerned purely with motivation for work, with little attention to possible new ideas in everyday problemsolving situations.

More recently, and in addition to related literature on human resource management (e.g. Binyamin and Carmeli, 2010; Snell and Dean, 1992) and social psychology (e.g. Bakker et al., 2008; Langelaan et al., 2006), several arenas of inquiry have been developed that delve into the specifics of mainstream management theories directly related to creative participation.

\section{Organizational Citizenship Behaviour}

Organizational citizenship behaviour (OCB) begins with Katz's (1964) identification of three basic types of behaviour, one of which is particularly relevant to the current understanding of $O C B$ and the proposed view on the willingness to creatively participate. However, OCB's definitive beginnings are associated with Smith et al. (1983), Organ and Konovsky (1989). According to the former, much of OCB has an altruistic character culminating in prosocial behaviour, and as they suggest this is something other than productivity. Although indirectly, they recognize that individual differences affect OCB in a similar way as suggested here, but their focus is on generic altruistic behaviour rather than specific circumstances that require ideas generation and contribution (e.g. problem solving situations). Later Podsakoff et al. (2000) reach much further by recognizing induced change from voluntary acts of creativity and innovation directed towards improvement of tasks and organizational performance. Choi (2007) then shows that such change-oriented OCB is significantly influenced by strong corporate vision and innovative climate, but acknowledges that: "The present study, however, did not include individual characteristics that might interact with contextual variables to influence employees' inclination to suggest constructive changes" (Choi, 2007, p.482). Although Bettencourt (2004) investigates situational influencers and individual disposition variables, and finds that they are both significant positive antecedents of change-oriented OCB, the study itself relates to a very narrow context of retail associates recognizing that work-role innovative behaviours are not yet fully considered. Perhaps LePine and Dyne (2001) are the closest to understanding willingness to creatively participate by showing that some individual characteristics lead employees to be more willing to either engage in conversations about improvement ideas or speak up and be counted.

\section{Creativity and Innovation}

Whilst OCB scholars study behavioural constructs and recognize that they are underpinned by individual commitment to behave in a particular way, they do not investigate creative participation as such. On the other hand, there are theoretical and empirical reasons to seek relevance in studies of creativity and innovation to better understand the role and the nature of willingness to contribute ideas.

Drivers for employees' intrinsic willingness to contribute and not just generate ideas have gained increased attention by those who recognize their importance for innovation (Morgan and Wang, 2010; Stüer et al., 2010). Furthermore, Van de Ven et al. (2008) and West (2001) consider ideas generation and their implementation as two distinct stages. Scott and Bruce (1994), Van Dijk and Van den Ende (2002) are even more specific by acknowledging that ideas need to be developed and shared with individuals and teams responsible for their implementation before they are implemented. They further find that ideas could be lost and innovation, regardless of its manifestation, would never even be born if employees are unwilling to make their contribution. This kind of an internal brain-drain is difficult to measure and is often unaccounted for, inevitably resulting in reduced competitiveness against organizations that manage to align themselves more closely with their employees' individual approaches (Chell and Athayde, 2009). All of this indicates that willingness/unwillingness to creatively participate is a construct that is well embedded in the literature, but lacks explicit recognition. Most studies provide implicit evidence that willingness to creatively participate is a fundamental requirement for an idea to become a constitutive component of innovation. This interface between ideas generation and their implementation has been recognized in some of the more recent studies. Martínez-Sánchez et al. (2011), 
Howell and Boies (2004) and Janssen (2003) have distinguished "ideas promotion", "championing individuals", "ideas development" and so on as a separate stage. However, the role and the nature of these phases in relation to creativity or innovation are still somewhat unclear. For instance, one of the key unanswered questions is what stimulates willingness to creatively participate. There is clearly an agreement in the literature that contextual, as well as personal factors should be taken into consideration, whether one studies $O C B$, creativity or innovation. positive correlation between all of these factors and innovativeness (Adair, 1990; Glynn, 1996; Kanter, 1983; Quinn, 1985; West, 2001).

Willingness to creatively participate may well be influenced by similar factors, but there might also be other factors that would otherwise have no effect on one's ability to generate or implement ideas. This study examines the existence of the impact of various factors on willingness to contribute ideas from the viewpoint of employees who are involved in the processes of transformation. ganisation can represent an enabler by helping to recognise, develop and implement individual contributions. Figure 1 illustrates a proposed framework of the presented antecedents of willingness to creatively participate as a dynamic interface between creativity and innovation.

\section{Knowledge and Understanding}

Although it is not the purpose here to study knowledge per se, it can be defined from the cognitive perspective as a collection of facts where knowing is a self-referential state, whilst understanding is a human ability to gain the meaning

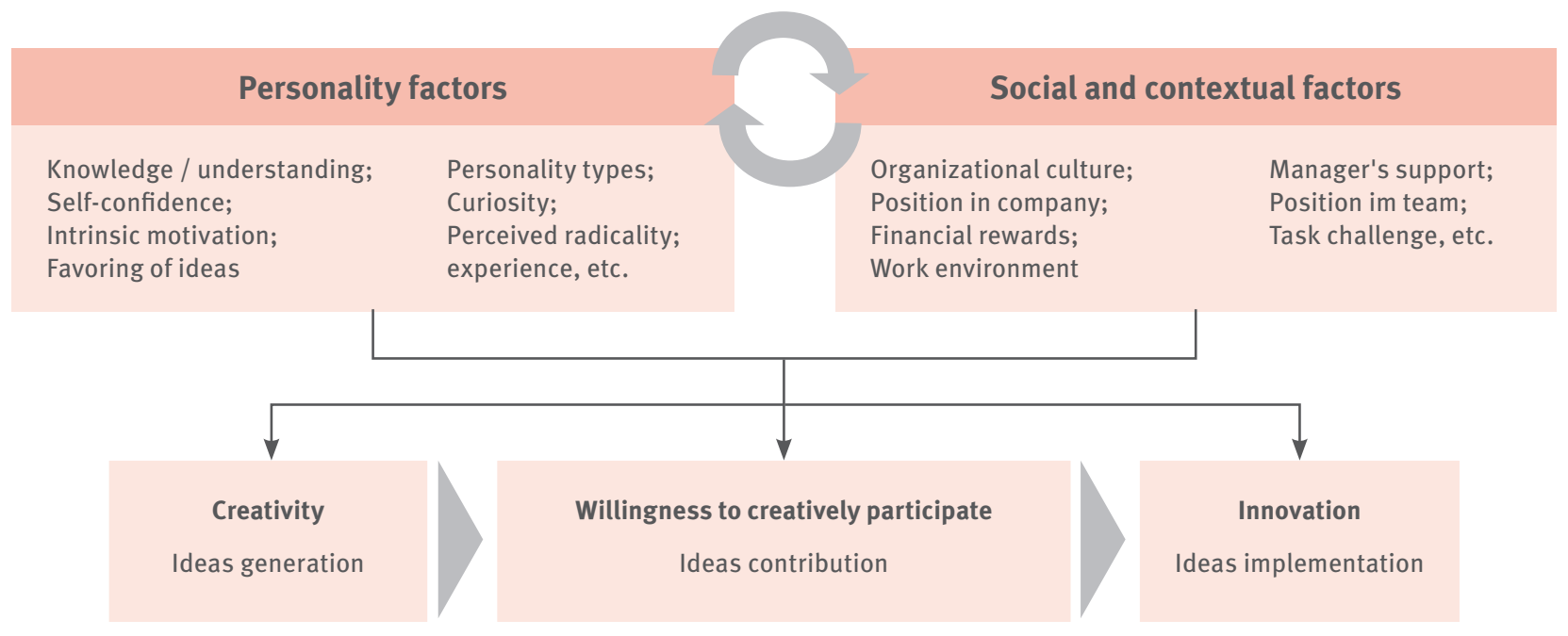

Figure 1 Willingness to creatively participate as an interface between idea generation and idea implementation

Human creativity and innovativeness are necessarily based on intrinsic personality characteristics where organizational settings help or hinder further development and transformation of ideas into meaningful solutions. Barron and Harrington (1981), Csikszentmihalyi (1992), Feist (1998), Furnham et al. (2009) and Weisberg (1999) all found a positive correlation between creativity and personal factors like knowledge, intrinsic motivation, curiosity, intelligence, self-confidence and personality types. These findings were also reaffirmed by Amabile (1996), Oldham and Cummings (1996), and Shalley et al. (2004). Although they include flexibility, innovation scholars have also found

\section{Antecedents of Creative Participation and Hypotheses}

Following from the aforementioned literature, willingness to creatively participate could be dependent upon employees' personal characteristics and contextual influences. On one hand environmental factors at the team and organizational levels, including organizational culture and climate, support and encouragement, are the ones that influence willingness to make creative contributions, but personal characteristics should also be taken into consideration (Delbridge and Whitfield, 2001; Woodman et al., 1993). Being “willing" could, therefore, be based on intrinsic personal characteristics, whilst an or- of acquired knowledge by interconnecting seemingly disconnected knowing through experience (Luhmann, 1990; Newton, 1996). Creative ideas can be generated regardless of the level of knowledge, but it can be tremendously difficult if not impossible to independently contrast their value in a particular problem-solving situation (Glover et al., 1989). This is supported by Sternberg et al. (1997) who found a positive correlation between knowledge and creativity. Knowledge has also been emphasized as a necessary component for effective group interactions and exchange of ideas (Ahmed, 1998). The influence of knowledge on one's willingness to creatively participate is, therefore, expected in the following manner: 
Hypothesis 1a: Employees with greater knowledge and understanding of a particular activity will be significantly more willing to generate and contribute ideas that relate to this activity than employees with less knowledge and understanding of the activity.

\section{Perceived Radicality of Ideas}

If the above hypothesis is confirmed, we would further expect that knowledge will play a role when it comes to a question of how radical a particular idea is from a viewpoint of an employee involved in an activity with all of its inputs, processes of transformation and outputs. The notion that ideas can be more or less radical is not new. Radicality in some instances (Bessant and Tidd, 2007) and radicalness in many others (Damanpour, 1988) are defined, but only from an external observer's viewpoint. There are even some who intentionally evade providing a unified definition to avoid further confusion that exists in the literature (Ehrnberg, 1995; Silverberg, 2002). In most cases changes are viewed either as radical or incremental, whether they focus on technical content or outputs of a production process. However, individuals involved in a particular production process may have views on such changes that significantly differ from those of external observers. Despite its inherent limitations, the objectivist description of production processes through Input-Process-Output (IPO) models was widely applied in scientific management spilling over to modeling team effectiveness and innovation processes (e.g. Barrick et al., 1998; Curral et al, 2001). Nevertheless, whilst recognizing that viewing changes as more or less radical is inherently subjective, no attempt has been identified that would look at creative changes within the IPOdefined production processes from a viewpoint of an employee involved in the processes of transformation.

From an employees' viewpoint, some ideas may well yield much more profound changes, whilst others may result in incremental and hardly visible adjustments, none of which could be visible to an external observer. In essence, they can vary in terms of a degree to which the idea reflects an incremental versus radical change and can relate to problems, products, organizational structures and services (Halinen et al., 1999; Mumford and Gustafson, 1988). Such on the go ideas may not yield any visible change in the outcome, nor substantiate new information or knowledge, and may pose very limited risk with little or no additional costs. So far differentiation in the form of radicalness has mostly been made in relation to an end product of the innovation process (Damanpour, 1988; Rice et al., 2001). Radicalness has been defined in various different ways (i.e. degree of change, novelty, requirements of new information and knowledge, and in terms of risk and cost). However, creative participation does not necessarily relate just to an end result of innovation in its purest sense and can also represent responses to every day problem solving situations that may not even be recognized as innovations. It is for this reason that radicality of ideas construct could be utilized when changes materialize within processes of transformation without any visible differences in outputs from the perspective of those involved in the processes of transformation. By constituting processes of transformation, employees may have very different perceptions of the radicality of ideas compared to external observers, and that could represent a barrier to creative participation. Some employees may have little reservation in contributing highly radical ideas, whilst others could find even a prospect of sharing a perceived highly radical idea with work colleagues or line managers unimaginable. We therefore suggest that the IPO models can be applied to investigate perceived radicality of ideas from a viewpoint of individuals involved in the processes of transformation in the following way:
Hypothesis 1b: Employees with greater knowledge and understanding of a particular activity will be significantly more willing to generate and contribute higher radical ideas that relate to this activity than employees with less knowledge and understanding of the activity.

\section{The Big Five Inventory}

It needs to be acknowledged that personality traits, assessments and more specifically the BFI have historically received a lot of criticism (e.g. Block, 1995; Gentry et al., 2007). However, more recent support and evidence show that the BFI has emerged as the paradigm for studying personality traits and their wider influence (John and Naumann, 2010). In addition and against the prevailing skepticism (e.g. Low and MacMillan, 1988), numerous recent entrepreneurship studies reveal that personality traits play a role when it comes to entrepreneurs' ingenuity (Marcati et al, 2008; Rauch and Frese, 2007). Similar findings span across innovation and creativity related research as well (Barron \& Harrington, 1981; Gough, 1957; Sternberg, 1999). Furnham et al. (2009), for instance, found creativity to be positively correlated with Extraversion, Openness to Experience and negatively to Agreeableness. Batey et al. (2009), on the other hand, have found that only Openness to Experience is positively correlated with creativity, whilst there is a negative correlation between Neuroticism and creativity. Nevertheless, there is evidence that sometimes certain behaviours are misinterpreted as personality traits (Morris et al, 1999). The limitations of personality assessments on one hand and recent support on the other have led us to include the $\mathrm{BFI}$ as it may show personality differences in relation to willingness to creatively participate:

Hypothesis 2: Taking into account the BFI, employees who are of a particular personality dimension generate and contribute significantly different numbers of ideas than employees of other personality dimensions. 


\section{Favouring of Ideas}

Favouritism to the sources decision-makers trust is well documented, particularly in the entrepreneurship literature. Zahra et al. (2006), for instance, show that whilst trust is recognized as conducive to entrepreneurial activities, excessive relational trust often leads to favouritism where ideas are only accepted from trusted sources. This is seen as particularly detrimental to new venture development where promoters of often radical ideas have to work hard to win recognition from the management (Kanter, 1983). Zahra et al. (2006) further suggest that in order to maintain trust champions of new ideas may themselves become biased favouring those ideas that their managers like. Favouritism of this kind is not limited just to entrepreneurs and has been reported in groups where members of a particular group would favour their own ideas over ideas suggested by members of other groups (Moscovici and Zavalloni, 1969; Nishii and Goncalo, 2008). Burgelman and Grove (1996) provide an even deeper insight by showing that high-influence parts of an organization benefit from such favouritism at the expense of units at the periphery, a form of intra-organizational provincialism.

The protective behaviour expressed through favouring may be a result of value-claiming as reported by Edmondson et al. (2003), but it could also stem from different personal characteristics. An individual may have an optimal idea that would solve a particular problem, but for some reason favours a less optimal one. In addition, the other team members may be similarly restrained favouring potentially less disruptive and also suboptimal ideas. Contributions of a series of sub-optimal ideas may thus result in a sub-optimal solution. All of this indicates that favouring of ideas could potentially influence willingness to creatively participate in the following way:

Hypothesis 3: When employees generate several alternative ideas they would be more willing to contribute their favourite ideas depending on whom these ideas would be contributed to within and outside of the organization.

\section{Methods and Experimental Design \\ Overview of Methods and Design}

To test the abovementioned hypotheses, a nonrandomized between-participants quasi-experimental design that involved several experimental tasks and a series of questionnaires is applied. The independent variables that were manipulated through the experimental tasks were knowledge and understanding (low, medium, high), perceived radicality (low, medium, high), five personality dimensions by the BFI (Extraversion, Consciousness, Openness to Experience, Agreeableness and Neuroticism) and favouring of ideas (5-point Likert-type scale from "do not like very much" to "like very much"). On one hand, experiment was necessary because no data on willingness to creatively participate currently exists. In addition, an experiment offers an opportunity to manipulate a set of variables in controlled conditions and could also include questionnaires and/ or interviews (McGuigan, 1978). Unfortunately, not many studies on creativity and innovation include any form of experiments (Sternberg, 1999). Although providing a greater amount of analyzable data, the exclusive use of surveys and interviews is overly subjective. They depend on snapshot style self-reports of human behaviour and provide the researcher less control over the situation under investigation (De Vaus, 2002; Furnham, 2005). Similarly, lack of control and a time scale are the two major drawbacks of purely ethnographic observations, although they may provide a qualitative insight rarely available through other methods.

The crux of the experiment was to trigger a creative process and then evaluate employees' willingness to contribute ideas. It involved images of three different, but equivalent structures and participants were asked to generate as many creative changes or improve- ments as possible. “Taipei 101" (building structure), "The Great Belt East Bridge" (bridge structure) and "Queen Mary II" (ship structure) are the three structures representing three different industrial sectors that were selected according to a set of equivalence criteria which were necessary to ensure comparable depiction of the three structures.

Because the distribution of the population is unknown the data needed to be analyzed using a suitable nonparametric method. Friedman ANOVA test was used in the investigation of knowledge/understanding differentiation. Box plots have been used to visually present the factors that drive participants to contribute ideas showing range, median, mean and quartiles.

\section{Sample}

We invited construction professionals with experience limited to building construction and non-construction professionals with no construction or any other engineering experience. The non-random sample was composed of the 76 individuals to participate in the experiment, 38 were from construction companies (experimental group) and 38 were from non-construction companies (control group). They come from a number of different countries (UK 29\%, Continental Europe $16 \%$, China $15 \%$ and other countries $40 \%$ ). The age of the participants across two groups ranged from 21 to 54 years (average 31 years). At the time of the experiment, $32 \%$ of participants were senior managers, $27 \%$ junior/middle managers and the other $41 \%$ holding non-managerial positions with average company tenure of 5 years.

The groups were deliberately diverse to minimize confinement to a particular social or cultural background and whilst none of these age and cultural parameters was taken into consideration, they represent substantial diversity that could potentially lead to generalization through further non-randomized and randomized investigations beyond the scope of this study. 


\section{Dependent and Independent} Variables

Manipulation of independent variables is based on differentiation within each of the factors representing an individual variable (see Figure 2). The differentiation of this kind improves the ability to manipulate variables, but even more importantly it enables investigating effects of such manipulations on the observable dependent variable.

Although the procedure itself is presented later in the paper, some reference to procedural reasoning and approaches have to be revealed earlier for better illustration of included variables.

Willingness to creatively participate. Participants' willingness to creatively participate represents a dependent variable to be measured as the number of contributed ideas to different groups of people, and depending on their knowledge/understanding, perceived radicality, favouring and personality dimensions by the BFI. Implicit measures are used because they are less prone to conscious control and they have been widely used in psychology literature (Dunn, 2009). For instance, participants were unaware that there were expert and non-expert groups in the experiment. They were also unaware that ideas prepared in advance were presented in a random order in terms of their radicality.

Knowledge and understanding. To manipulate this independent variable, the experiment involved equal sized construction and non-construction groups (equivalence criterion I in Figure 2) who were asked to use equivalent images and technical descriptions of “Taipei 101", "The Great Belt East Bridge" and "Queen Mary II" (equivalence criteria II in Figure 2). The selection of the two groups and their knowledge in relation to the three equivalent structures were the two knowledge/ understanding differentiations. In essence, construction participants are assumed to have profound knowledge
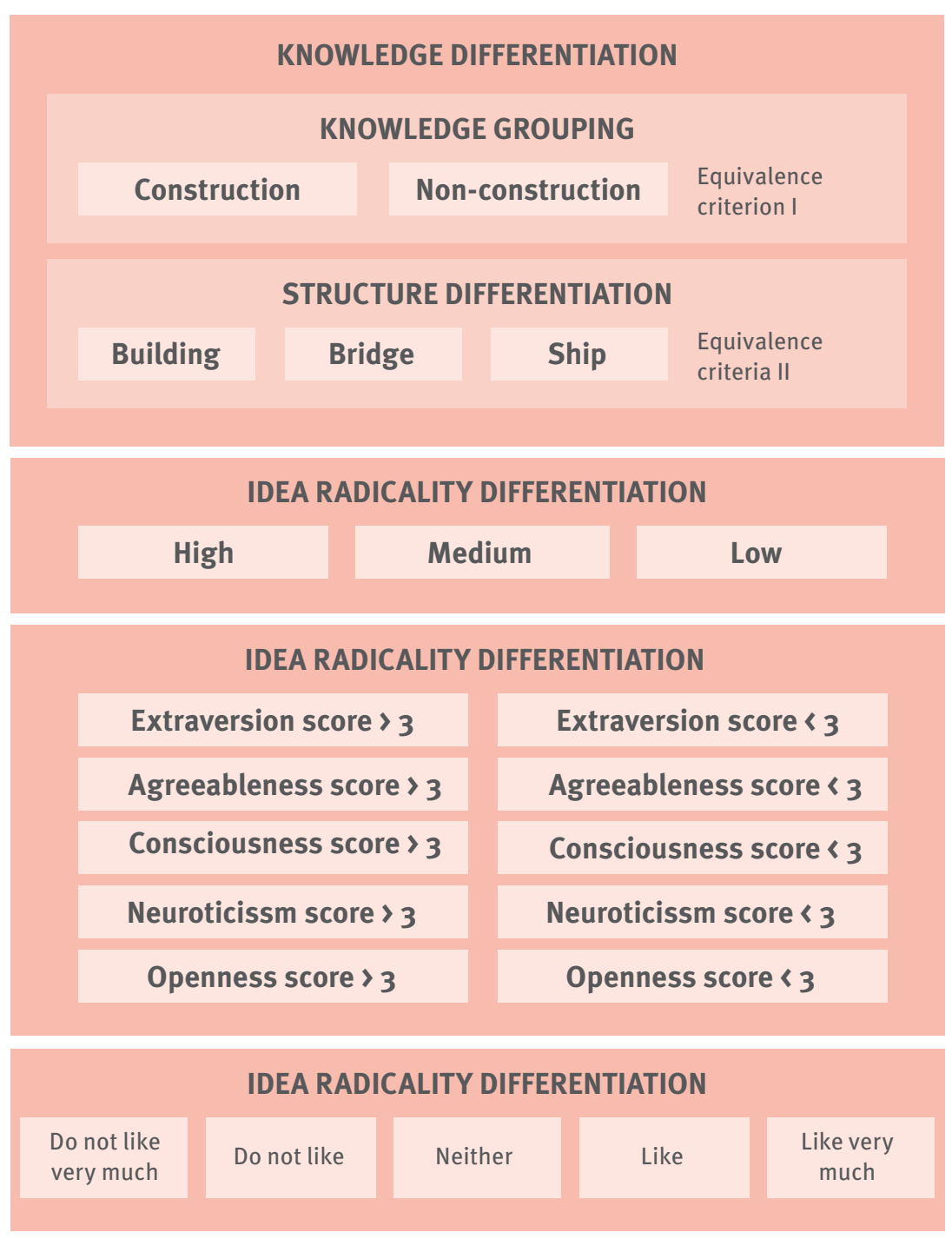

\section{WILLINGNESS TO CREATIVELY PARTICIPATE}

\section{Figure 2 The differentiation within each of the identified variable}

of buildings, some knowledge of bridge structures, but have very little expert knowledge of ship construction. Selected non-construction participants formed a control group with equivalently very little expert knowledge of all three structures.

Failure to achieve the equivalence results in confounding and is a situation in which something other than independent variable may be responsible for differences in dependent variable (Axelrod, 1999), so the structures were selected according to the following equivalence criteria:
Status equivalence: status equivalence ensures that representation of structures does not bias the experimental task performance; the three structures are well known for their superlatives when built, but all of them have since been superseded by other structures making their status equivalent; "Taipei 101 " is one of the tallest buildings in the world, "The Great Belt East Bridge" is one of the longest bridges in the world and "Queen Mary II" is one of the biggest ships in the world.

Orientation and distance equivalence: images of the three structures 
are all shown to participants from an angle of no more than 45 degrees (front view, front view from a distance and lateral view). Three same-size colour images of the three structures are given to participants to ensure visual equivalence.

- Description equivalence: each structure is also supported with a brief description of equivalent length and detail; the major components for each of the three structures are general characteristics, technical information, construction technology including support structure, superstructure, construction methods and exterior design.

Perceived radicality of ideas. The simple IPO model of a production process has been adopted to suggest and test the three levels of radicality (low, medium, high). Highly radical ideas as opposed to those of lower radicality may result in changes to one or more IPO stages. For instance, some changes in inputs may or may not require changes in the processes of transformation, but may also not result in a visibly changed output. Using mathematical analogy, radicality can be assigned $n$ levels, but for simplicity only low, medium and high levels of radicality are proposed. It is suggested here that in relation to the IPO model and employees involved in the processes of transformation, a low level of radicality would represent only a change in inputs or in the visual appearance of an output. Highly radical ideas, on the other hand, would include changes to inputs, processes of transformation and a change in visual appearance of an output. In addition, it has to be emphasised again that radicality is here defined as a measure of change as seen by employees that are involved in the processes of transformation.

To test the suggested levels, six ideas were prepared in advance for each of the three structures, two of which correspond to each of the proposed levels of radicality. Ideas were presented in a random order to ensure that participants were unaware of this pre-categorisation.

Personality dimensions by the Big Five Inventory. Participants are differentiated by the BFI personality dimensions (John et al., 2008). Using the BFI enables an investigation of the differences in the numbers of contributed ideas by employees of different personality dimensions and their effect on the willingness to creatively participate. In this particular case the main role of the $\mathrm{BFI}$ is not to distinguish various personalities per se, but rather to elicit personality based categorisation in order to determine differences in willingness to creatively participate.

Perceived favouring of ideas. Favouring of ideas surfaces when an individual has more than one idea for a particular problem, but favours one or more ideas over the set of available alternatives. It may not only relate to employees' own generated ideas, but also to the ones contributed by work colleagues. Participants need to reveal their favouring preferences by ranking prepared ideas in advance using the 5-point Likert-type scale to establish a link between their willingness to creatively participate and favouring preferences.

\section{Procedure, Sequencing and Timing}

Sequencing is a factor that can affect the nature of participants' responses (Goodwin, 2009). Their earlier reactions to some issues, especially ones that are directly related to the research topic, can alter the responses and performance that follow later in the experiment. Participants were intentionally not informed about the details of the research in order to achieve a higher level of objectivity.

The sequence starts with instructions about the whole session specifying settings for experimental tasks, ensuring that the sequence remains procedurally intact. Avoiding fatigue and giving all participants the same amount of time were two major criteria for allocating fixed time intervals (Barnes and Seymour, 1980). The 5-minute introduction is followed by the background questionnaire stage with basic sampling-specific questions, which is then followed by the first experimental task. The tasks involving the three structures were intentionally interspersed by short breaks allowing participants to relax from a particular task and minimize potential inter-task influencing. The second experimental task is followed by questionnaire on willingness to creatively participate that aims to evaluate factors perceived to be significant for ideas contribution. The BFI personality inventory is the final stage. These last two sets of questionnaires were intentionally placed after experimental tasks at the end of the whole procedure because they, to a certain extent, reveal the nature of the study and could influence behaviour if introduced earlier.

Experimental tasks. The first experimental task required participants to generate as many creative ideas that would either change or improve the three structures as possible. The participants were asked to make improvements as if they are about to start building a structure shown on a series of equivalent images and accompanying descriptions. Such a visual representation is particularly useful in the experiment for better understanding of given information (LeGrand, 1990).

The second experimental task required participants to (1) evaluate ideas by their radicality and (2) self-report their willingness to contribute these ideas to different groups of people. First, they were asked to examine their own generated ideas from the first task and ideas that were prepared in advance in order to categorize these by their level of radicality (low, medium and high). Ideas were randomly distributed, so that the experimenter could not tell which ideas selected by participants were low, medium or highly radical. Second, participants were asked to select people or groups to whom they would be willing to contribute their own gen- 


\begin{tabular}{|c|c|c|c|c|c|c|c|c|c|c|c|c|}
\hline & $\begin{array}{c}\text { Line } \\
\text { managers' } \\
\text { support }\end{array}$ & $\begin{array}{l}\text { My overall } \\
\text { skills }\end{array}$ & $\begin{array}{l}\text { Team } \\
\text { culture }\end{array}$ & $\begin{array}{l}\text { Financial } \\
\text { rewards }\end{array}$ & $\begin{array}{l}\text { Intrinsic } \\
\text { motivation }\end{array}$ & Curiosity & Knowledge & $\begin{array}{c}\text { Self- } \\
\text { confidence }\end{array}$ & Experience & $\begin{array}{c}\text { Position in } \\
\text { the company } \\
\text { Construction } \\
\text { problems }\end{array}$ & $\begin{array}{l}\text { Position in } \\
\text { the team }\end{array}$ & $\begin{array}{l}\text { Level of } \\
\text { radciality }\end{array}$ \\
\hline $\begin{array}{l}\text { Line } \\
\text { managers' } \\
\text { support }\end{array}$ & 1.000 & & & & & & & & & & & \\
\hline $\begin{array}{l}\text { My overall } \\
\text { skills }\end{array}$ & 0.120 & 1.000 & & & & & & & & & & \\
\hline Team culture & 0.273 & 0.402 & 1.000 & & & & & & & & & \\
\hline $\begin{array}{l}\text { Financial } \\
\text { rewards }\end{array}$ & 0.187 & 0.059 & 0.194 & 1.000 & & & & & & & & \\
\hline $\begin{array}{l}\text { Intrinsic } \\
\text { motivation }\end{array}$ & 0.248 & 0.353 & 0.441 & 0.294 & 1.000 & & & & & & & \\
\hline Curiosity & 0.092 & 0.546 & 0.315 & -0.048 & 0.627 & 1.000 & & & & & & \\
\hline Knowledge & -0.013 & 0.591 & 0.339 & 0.020 & 0.632 & 0.739 & 1.000 & & & & & \\
\hline $\begin{array}{c}\text { Self- } \\
\text { confidence }\end{array}$ & 0.067 & 0.525 & 0.239 & 0.295 & 0.512 & 0.454 & 0.544 & 1.000 & & & & \\
\hline Experience & -0.009 & 0.439 & 0.135 & 0.267 & 0.503 & 0.397 & 0.472 & 0.700 & 1.000 & & & \\
\hline $\begin{array}{l}\text { Position in } \\
\text { the company } \\
\text { Construction } \\
\text { problems }\end{array}$ & 0.191 & 0.196 & 0.262 & 0.524 & 0.301 & 0.081 & 0.018 & 0.416 & 0.540 & 1.000 & & \\
\hline $\begin{array}{l}\text { Position in the } \\
\text { team }\end{array}$ & 0.279 & 0.090 & 0.183 & 0.364 & 0.208 & 0.057 & -0.060 & 0.311 & 0.259 & 0.678 & 1.000 & \\
\hline $\begin{array}{l}\text { Level of } \\
\text { radciality }\end{array}$ & 0.094 & 0.217 & 0.371 & 0.412 & 0.493 & 0.286 & 0.315 & 0.316 & 0.356 & 0.531 & 0.440 & 1.000 \\
\hline
\end{tabular}

Table 1 Inter-item correlation matrix for Cronbach's Alpha reliability for personal and organizational factors as drivers for employee willingness to creatively participate

erated ideas. Immediate superior, team leader, work colleagues, potential investors and business partner have been selected because they are related to employee's work and often make decisions about contributed ideas (Van de Ven et al., 2008). This was contrasted with friends and relatives groups because they may not be directly involved in any decision making processes. In the final stage of the second task participants were asked to indicate their favouring preference for ideas prepared in advance.

Series of questionnaires. Questionnaires were used in conjunction with experimental tasks in order to allow the researcher to formulate personality dimensions, ideas contribution and evaluation very specifically (Furnham, 2005). Questionnaires formed a three- part series to be completed at different stages during the experiment. The first part includes general information about participants and their working experience and introduced before experimental tasks. The second part was introduced after the experimental tasks and directly relates to willingness to creatively participate and evaluation of personal and organizational factors perceived as important ideas contribution. The third part is the BFI personality inventory introduced at the very end.

\section{Results}

\section{Reliability}

The Cronbach's a has been used for the purpose of identifying the reliability of adopted scales in the questionnaires. The value of Cronbach's a of 0.7 to 0.8 is acceptable value indicating internal consistency (Field, 2009). Kline (1999) stated that when studying psychological constructs values below 0.7 can be expected because of the diversity of the constructs being measured. The result for Cronbach's a for the subscales in the questionnaire for factors perceived as important for employees' willingness to creatively participate is 0.831 indicating adequate reliability (see Table I).

\section{Personal or Organizational Factors?}

Figure 3 shows box plots for participants' evaluation of factors that could impact employees' willingness to contribute ideas based on a 5-point Likerttype scale, obtained from the second part questionnaire. In general, personal factors (dark grey) are evaluated as more important than organizational ones (light grey). Intrinsic motivation, 


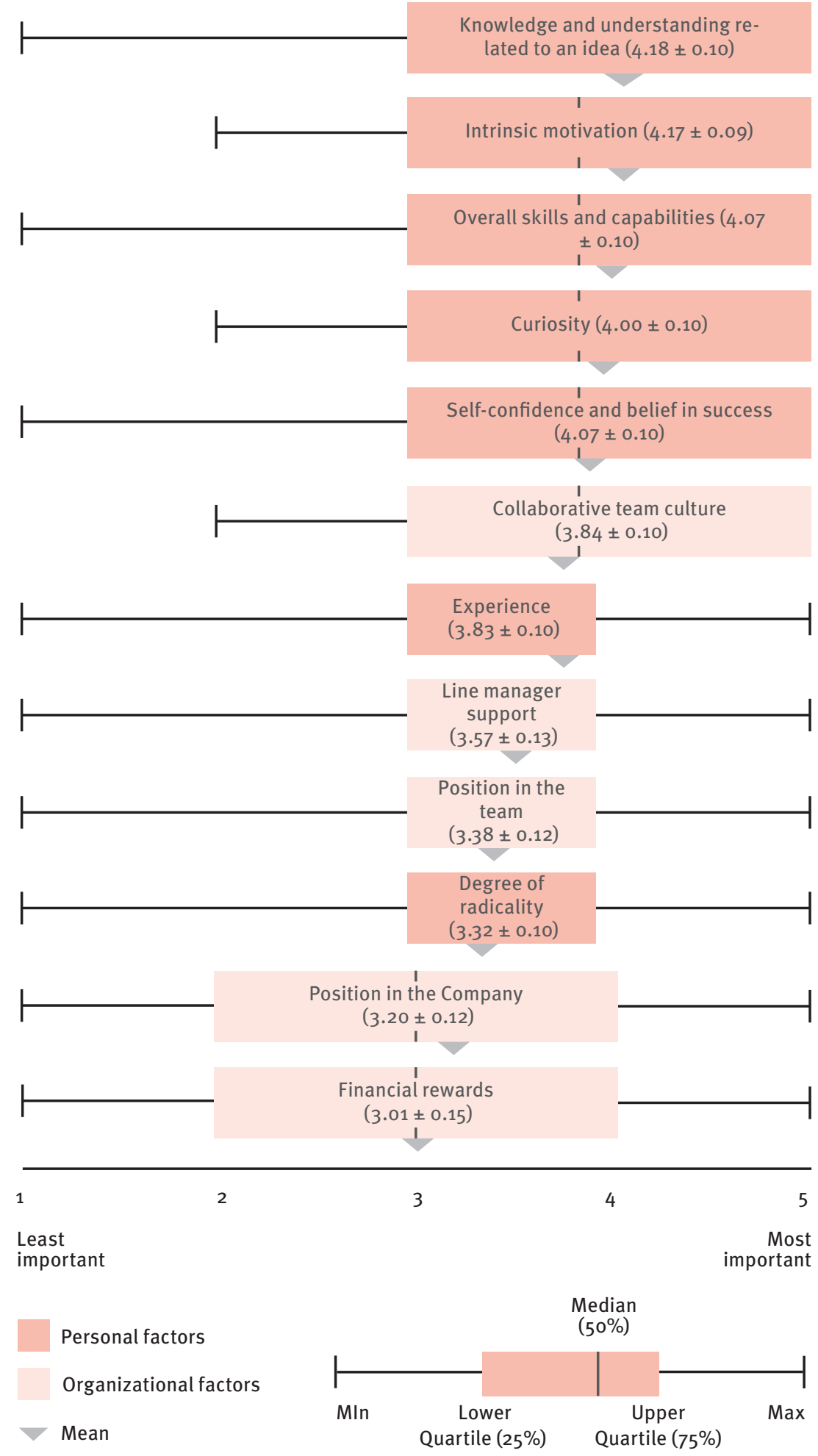

Figure 3 Box plots of data including participants' mean values, standard error values for drivers considered for employees' willingness to contribute ideas knowledge/understanding and curiosity have been found to be more important for participants' willingness to contribute ideas than position in the company and financial rewards.

\section{Knowledge/Understanding, Radicality and Willingness to Creatively Participate}

Table II shows the number of generated ideas in the first experimental task for the three given structures. Each structure corresponds to a different level of knowledge in relation to a group of construction participants.

In regards to creativity the results show that construction participants generated more ideas for the structure they are assumed to be most knowledgeable about (building), less ideas for the structure they are somewhat familiar with (bridge) and the lowest number of ideas where they have no experience and comparatively low level of knowledge (ship). In contrast, nonconstruction participants show greater uniformity in their creative output supporting the assumption that they have very little technical knowledge of all three presented structures. In total, they generated fewer ideas for all structures and, unlike construction participants, with no significant differences between the numbers of ideas for each of the structures.

Second, in relation to their willingness to creatively participate, participants were asked to identify groups of people with whom they would be willing to share the generated ideas. Closer examination, particularly in relation to levels of radicality for the building structure, shows a clear difference between construction and non-construction participants. Figure 4 presents the distribution of ideas from construction and non-construction participants to different groups of people by levels of radicality. Construction participants showed greater willingness to contributing ideas of high radicality to all groups of people. Non-construction partici- 


\begin{tabular}{|c|c|c|c|}
\hline & $\begin{array}{c}\text { Building (high } \\
\text { knowledge) }\end{array}$ & $\begin{array}{c}\text { Bridge (medium } \\
\text { knowledge) }\end{array}$ & $\begin{array}{c}\text { Ship (low } \\
\text { knowledge) }\end{array}$ \\
\hline Construction participants & 111 & 83 & 67 \\
\hline Non-construction participants & 50 & 79 & 70 \\
\hline
\end{tabular}

Table 2 The numbers of generated ideas for three structures with different levels of knowledge by construction and non-construction participants

pants principally resorted to contributing ideas of low and medium radicality, with an exception of business partners where they show greater willingness to creatively participate although this large difference is difficult to explain. The results for the bridge structure show that construction participants are more cautious regarding their willingness to creatively participate with highly radical ideas. They are more willing to contribute ideas of medium radicality and to people within their working environment. In this particular case non-construction participants shy away from business partners, but the distribution in regards to idea radicality levels is still in favour of low radicality. The results for ship structure show that construction participants are even less willing to creatively participate with highly radical ideas and predominantly stand by those of low or medium radicality. Interestingly, non-construction participants are slightly more radical in this particular case, but overall looking at results willingness to contribute ideas increases with knowledge, and so does the willingness to contribute ideas of higher radicality levels that support Hypotheses $1 \mathrm{a}$ and $1 \mathrm{~b}$.

To strengthen this visual observation a statistical analysis has been conducted comparing the three structures. Friedman's ANOVA was used to assess the overall variability in the number of contributed ideas under differing levels of knowledge/understanding. The mean values and maximum numbers of contributed ideas are statistically higher for construction participants (2.92 - building, 2.18 - bridge and 1.76 - ship) than for non-construction (1.78 - building, 2.08 - bridge and 1.84 - ship). In particular, they are significantly higher for building structure where there is the highest level of knowledge/understanding differentiation. The weight of participants in experimental group significantly changed over the three experimental conditions $X^{2}(2)=24.843, p<.05$, whilst it did not change for the control group $\mathrm{X}^{2}(2)=5.621$, p >.05. Overall, knowledge/understanding in respect to an idea has a statistically significant effect on participants' willingness to creatively participate.

\section{The BFI Personality Dimensions and Willingness to Creatively Participate}

Figure 5 contrasts the BFI personality dimensions, i.e. Extraversion, Consciousness, Openness to Experience, Agreeableness and Neuroticism. The BFI was used to categorize participants by identified personality dimensions and the responses were distributed according to the willingness to generate and contribute ideas to different groups of people. This approach allows contrasting the numbers of generated and contributed ideas by each personality dimension regardless of their reliability as statistically significant differences would demand greater attention in the future. On average, participants with high extraversion, neuroticism and openness scores, and low agreeableness and conscientiousness scores created more ideas than their counterparts with low extraversion, neuroticism and openness scores, and high agreeableness and conscientiousness scores. However, results show no significant differences between participants' personality dimensions and their willingness to contribute the generated ideas to different groups of people and, therefore, Hypothesis 2 is rejected.
As a general rule, statistical difference could be established through correlation analysis for the BFI investigation, but the number of participants was too small, so the results are of informative nature only. Nevertheless, this could potentially lead to a separate longitudinal study involving far larger groups.

\section{Favouring of Ideas and Willingness to Creatively Participate}

Table III presents descriptive statistics for favouring of level $1 \& 2$ (below average) and $4 \& 5$ (above average) ideas based on the 5-point Likert-type scale (1-don't like very much and 5-like very much). In support of Hypothesis 3, on average, participants were more willing to contribute their favourite ideas (level $4 \& 5)$ to team leader, immediate superior, professionals, work colleagues, potential investors who are most likely involved in ideas implementation process. In the case of least favourite ideas (level 1\&2) they were more willing to contribute them to friends/relatives, work colleagues who are not responsible for any decision making, and much less to people directly responsible for ideas implementation.

\section{Limitations and Future Research Directions}

The limited number of participants is the most obvious limitation of this study. The small sample size is due to a selected quasi-experimental design engaging each individual for a considerable amount of time. Since most experimental studies on human behaviour, personality and social psychology use a minimum of thirty participants to get stable measures (Field, 2009; Ramachandran, 1994), the selected sample is of appropriate size to provide embryonic evidence of the factors that impact employees' willingness to creatively participate.

From a methodological standpoint, the study adopts a nonrandomized quasi-experimental research design which brings increased threats to valid- 


\begin{tabular}{|c|c|c|c|c|c|c|c|c|}
\hline \multicolumn{3}{|c|}{ Building } & \multicolumn{3}{|c|}{ Bridge } & \multicolumn{3}{|c|}{ Ship } \\
\hline High & Medium & $\square$ Low & High & Medium & Low & High & Medium & Low \\
\hline $\mathrm{NCC}$ & NC C & NC C & NC C & NC C & NC C & NC C & NC C & NC C \\
\hline $20 \% 48 \%$ & $32 \% 38 \%$ & $28 \% 14 \%$ & $51 \% 27 \%$ & $39 \% 48 \%$ & $12 \% 26 \%$ & $12 \% 22 \%$ & $52 \% 39 \%$ & $36 \% 39 \%$ \\
\hline
\end{tabular}

Non-construction

Construction
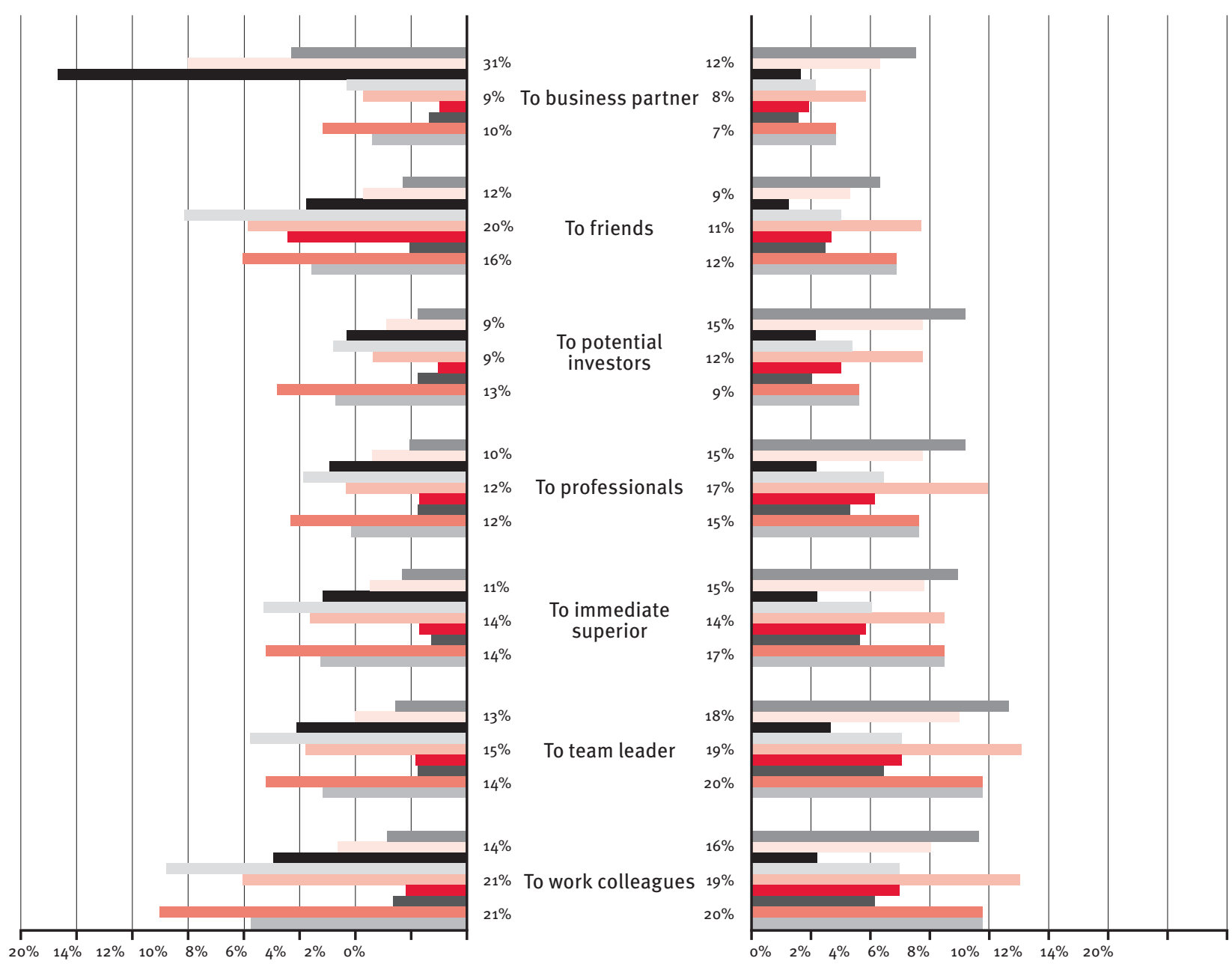

Figure 4 The numbers of contributed ideas to different groups of people by construction and non-construction participants for three structures by radicality (high, medium and low); one idea can be contributed to several groups of people

ity in comparison to true experiments. The quasi-experimentation was conducted over a period of several weeks because it was not possible to complete it with all 76 participants at the same time. This again may be viewed as a limitation that was diminished by ensuring that all experiments were conducted at the same time of the day and in almost identical conditions (e.g. room, location, temperature). To improve external validity the investigation will need to be repeated in different contexts and include factors beyond the ones presented here. For instance, cultural differences at team and organizational levels could also be considered. There is plenty of evidence in the studies of team dynamics that overall team effectiveness depends on individual performance and team configuration (see for example Gilson and Shalley, 2004; Payne et al., 2009). Nevertheless, the impact of the inherent dynamism in the willingness of individual team members to creatively participate on the overall effectiveness is still not entirely understood, and even a slight change of a team configuration may profoundly affect it.

Another limitation is that only the BFI was used which did not reveal any significant effects of personality dimensions on employees' willingness to contribute ideas. Future research may investigate these further using larger samples, and potentially a greater number of complementary personality inventories (e.g. Kirton Adaption-Innovation Inventory, Myers-Briggs Type Indi- 
(\%)
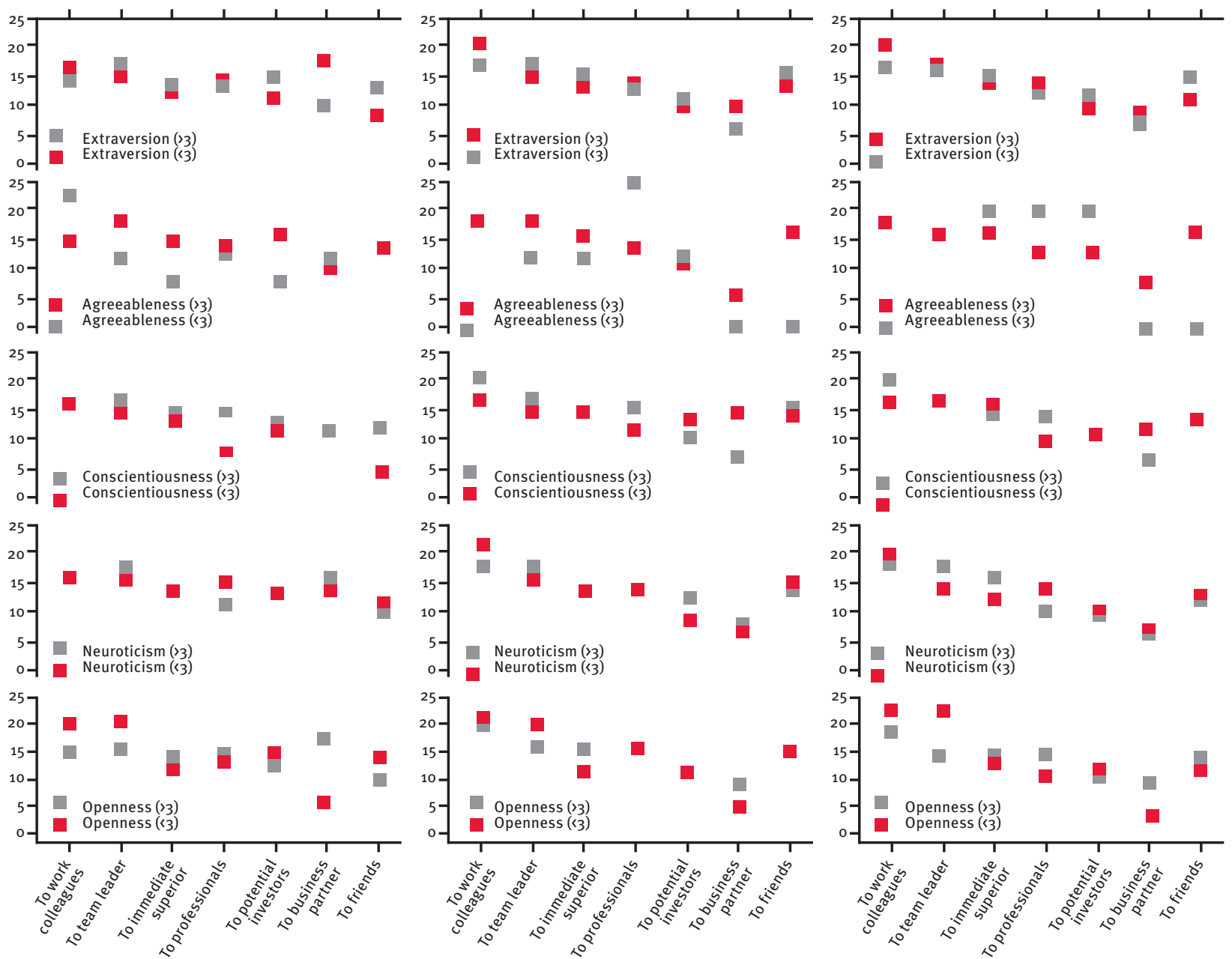

Figure 5 The relationship between the BFI personality dimensions (E score >3/E score $\mathbf{3}_{3}, \mathrm{~A}$ score $\rangle_{3} / \mathrm{A}$ score $\mathbf{1 3}_{3}, \mathrm{C}$

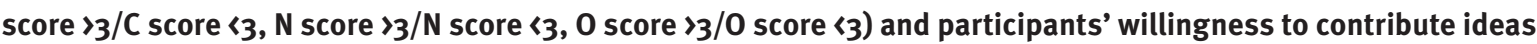
for building (left image), bridge (middle image) and ship (right image) structures; each dot shows the percentage of contributed ideas to each group of people; groups of people are sorted by required knowledge for ideas contribution from higher to lower; numbers in brackets represent the average number of generated ideas per participant; one created idea could be contributed to several groups of people

cator, NEO Five-Factor Inventory etc.) Similarly, radicality construct should receive greater attention in the future and, perhaps, more than three levels of radicality would be needed. In addition, the proposed IPO-based model could well be too simplistic for a more detailed classification.

The above suggested directions are neither exhaustive nor prescriptive, but they may lead to a more adequate portrayal of willingness to creatively participate and how it emerges and evolves in various organizational settings.

\section{Discussion and Conclusions}

This study shows that even if organizations provide supportive work environments, employees might not be willing to contribute ideas because of personality-induced mismatches. The higher value of personality-related factors for willingness to creatively participate over organisational factors is consistent with findings by Bunce and West (1995) who show that individual innovativeness depends more on personality factors than on employees' perceptions of social environment. Although from a different standpoint, Latham and Locke (1979) confirm that culturally disadvantaged employees who lack self-confidence may struggle in some organizational cultures. In the same way, a highly educated and proactive employee may struggle in an overly conservative risk-averse environment. Perhaps this indicates that companies should be thinking about the masscustomization of the work environment along the lines of flexible arrangements as discussed by Segars and Hendrickson (2000). Such arrangements would enable better utilization of individual 


\begin{tabular}{|c|c|c|c|c|c|c|c|c|}
\hline & & \multicolumn{7}{|c|}{ Building structure } \\
\hline & & $\begin{array}{l}\text { Friends / } \\
\text { relatives }\end{array}$ & $\begin{array}{c}\text { Work } \\
\text { colleagues }\end{array}$ & Team leader & $\begin{array}{l}\text { Immediate } \\
\text { superior }\end{array}$ & $\begin{array}{c}\text { Business } \\
\text { partner }\end{array}$ & Professionals & Investors \\
\hline \multirow{6}{*}{ 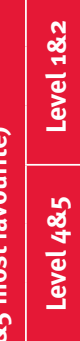 } & Mean & 51.48 & 52.29 & 33.87 & 28.76 & 19.36 & 31.18 & 21.10 \\
\hline & St. Dev. & 41.91 & 41.60 & 42.33 & 40.37 & 34.40 & 41.68 & 35.76 \\
\hline & St. E. & 4.81 & 4.77 & 4.86 & 4.63 & 3.95 & 4.78 & 4.10 \\
\hline & Mean & 44.80 & 63.85 & 68.92 & 54.53 & 37.60 & 52.33 & 40.63 \\
\hline & St. Dev. & 47.21 & 44.18 & 39.64 & 43.20 & 45.70 & 45.15 & 44.78 \\
\hline & St. E. & 5.41 & 5.07 & 4.55 & 4.96 & 5.24 & 5.18 & 5.14 \\
\hline \multicolumn{9}{|c|}{ Bridge structure } \\
\hline \multirow{3}{*}{ 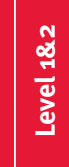 } & Mean & 49.06 & 51.45 & 32.82 & 25.54 & 15.56 & 30.46 & 18.95 \\
\hline & St. Dev. & 41.74 & 44.55 & 43.04 & 40.88 & 33.94 & 42.66 & 36.97 \\
\hline & St. E. & 4.79 & 5.11 & 4.94 & 4.69 & 3.89 & 4.89 & 4.24 \\
\hline \multirow{3}{*}{ 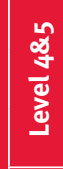 } & Mean & 49.08 & 66.79 & 70.82 & 59.03 & 42.22 & 60.51 & 50.05 \\
\hline & St. Dev. & 46.33 & 42.46 & 39.84 & 43.58 & 46.80 & 43.43 & 44.17 \\
\hline & St. E. & $5 \cdot 31$ & 4.87 & $4 \cdot 57$ & 5.00 & 5.37 & 4.98 & 5.07 \\
\hline \multicolumn{9}{|c|}{ Ship structure } \\
\hline \multirow{3}{*}{ 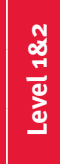 } & Mean & 53.60 & 49.97 & 31.21 & 25.99 & 13.63 & 22.63 & 19.78 \\
\hline & St. Dev. & 43.06 & 41.50 & 41.66 & 40.31 & 32.52 & 38.62 & 34.96 \\
\hline & St. E. & 4.94 & 4.76 & 4.78 & 4.62 & 3.73 & 4.43 & 4.01 \\
\hline \multirow{3}{*}{ 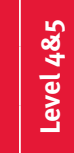 } & Mean & 54.15 & 64.55 & 66.98 & 59.37 & 44.89 & 62.09 & 50.50 \\
\hline & St. Dev. & 46.86 & $44 \cdot 32$ & 41.95 & 43.80 & 47.64 & 45.22 & 47.14 \\
\hline & St. E. & 5.37 & 5.08 & 4.81 & 5.02 & 5.46 & 5.19 & 5.41 \\
\hline
\end{tabular}

Table 3 Descriptive statistics showing mean, standard deviation and standard error in terms of a proportion of contributed ideas to the seven groups of people by their levels of favouring. Favouring of ideas is measured based on a 5-point scale (1-don't like very much to 5 -like very much)

capabilities and prevent the perils of one-size-fits-all initiatives.

From the perspective of employees involved in the processes of transformation, we investigate the relationships between personal factors and employee willingness to creatively participate. We also proposed radicality of ideas construct and test the predetermined IPO-based radicality levels (low, medium high).

In a between-subject quasi-experiments involving 76 participants, we manipulated knowledge and understanding (low, medium, high), perceived radicality (low, medium high), personality dimensions by the BFI, and favouring of ideas (levels 4 and 5 ). In relation to individual independent variables, the results show that willingness to contribute ideas depends on relevant knowledge/understanding (Hypothesis 1a). In particular and in relation to the building structure where construction participants are assumed to be experts, they were also more willing to contribute highly radical as opposed to medium or ideas of low radicality (Hypothesis 1b). The picture is less recognizable for non-construction participants who were approximately equally willing to contribute ideas of all levels of radicality for all given structures. Organizations clearly require participation of highly knowledgeable employees to increase contribution of more radical ideas with an ultimate goal of achieving radical in- novation (Leifer et al., 2001). Perhaps surprisingly, we did not find any effects of personality dimensions on the willingness to creatively participate ( $\mathrm{Hy}$ pothesis 2), which is clearly different to previous studies of creativity (Furnham et al., 2009). It is difficult to generalize the results from 76 participants, but nevertheless, this shows that people of all personality dimensions are more or less equally willing to contribute generated ideas. More creative people are perhaps found to be independent and with high aspirations as shown by Helson (1996), but they are not necessarily more willing to contribute their ideas. The results also show that although employees may generate several ideas 
for the same problem or situation, they might favour some ideas over everything else. In effect, favouring shows a profound effect on employee willingness to creatively participate, particularly in respect to decision-makers (Hypothesis 3).

Our results have important implications for the extant theories by revealing that employees' willingness to creatively participate depends on a number of personal factors. The results indicate that it is vital to study willingness to creatively participate separately from employees' creativity and innovativeness. These findings are in line with some studies of consumer willingness to participate in co-creation processes. We also find that radicality of ideas from the viewpoint of employees involved in processes of transformation significantly impact their willingness to creatively paprticipate. This finding is of particular importance for future research on radical innovation. More radical ideas are likely to come from directly involved and knowledgeable employees who have more profound understanding of the processes of transformation. Favouring of generated alternative ideas is a form of self protection that may have significant implications for future research of creative expression and innovativeness. Perhaps all these findings also indicate that managers should pay more attention to individual employees and steer away from one-size-fits-all initiatives. This could consequently lead to a better understanding of the impact the work environment has on employees' willingness to contribute ideas. Openness to all ideas, even when they are in the form of simple suggestions, could well path the way to an improved overall innovative capacity since this could open doors to willingness to contribute further ideas in the future and greater probability of generating successful innovations (Enkel et al., 2009; Lichtenthaler and Lichtenthaler, 2009).

\section{References}

Adair, J. (1990). The Challenges of Innovation. Guildford: The Talbot Adair Press.

Ahmed, P. K. (1998). “Culture and climate for innovation'. European Journal of Innovation Management, 1, 30-43.

Amabile, T. M. (1979). 'Effects of external evaluation on artistic creativity'. Journal of Personality and Social Psychology, 37, 221-233.

Amabile, T. M., Hill, K. G., Hennessey, B. A. and Tighe, E. (1994). 'The Work Preference Inventory: Assessing intrinsic and extrinsic motivational orientations'. Journal of Personality and Social Psychology, 66, 950-967.

Amabile, T. M. (1996). Creativity in Context. Boulder: Westview Press.

Anderson, H., Havila V., Andersen, P. and Halinen, A. (1998). 'Position and role-conceptualizing dynamics in business networks'. Scandinavian Journal of Management, 14, 167-186.

Axelrod, A. (1999). Ace Your Midterms \& Finals: Introduction to Psychology. New York: McGrawHill Professional.

Bakker, A. B. and Schaufeli, W. B. (2008). 'Editorial: Positive organizational behaviour: Engaged employees in flourishing organizations'. Journal of Organizational Behaviour, 29, 147-154.

Bakker, A. B., Schaufeli, W. B., Leiter, M. P. and Taris, T. W. (2008). 'Work engagement: An emerging concept in occupational health psychology'. Work \& Stress, 22, 187-200.

Barnes, J. H. and Seymour, D. T. (1980). 'Experimental bias: Task, tools and time'. Journal of the Academy of Marketing Science, 8, 1-11.

Barrick, M. R., Stewart, G. L., Neubert, M. J. and Mount, K. (1998). 'Relating member ability and personality to work-team processes and team effectiveness'. Journal of Applied Psychology, 83, 377-391.

Barron, F. and Harrington, D. (1981). 'Creativity, intelligence, and personality'. Annual Review of Psychology, 32, 439-476.

Batey, M., Chamorro-Premuzik, Y. and Furnham, A. (2009). 'Intelligence and personality as predictors of divergent thinking: the role of general, fluid and crystallized intelligence'. Thinking Skills and Creativity, 4, 60-69.

Bessant, J. and Tidd, J. (2007). Innovation and Entrepreneurship. West Sussex: John Wiley \& Sons Ltd.

Bettencourt, L. A. (2004). 'Change-oriented organizational citizenship behaviours: The direct and moderating influence of goal orientation'. Journal of Retailing, 80, 165-180.
Binyamin, G. and Carmeli, A. (2010). 'Does structuring of human resource management processes enhance employee creativity? The mediating role of psychological availability'. Human Resource Management, 49, 999-1024.

Block, J. (1995). 'A contrarian view of the fivefactor approach to personality description'. Psychological Bulletin, 117, 187-215.

Bunce, D. and West, M. A. (1995). 'Self Perceptions and Perceptions of Group Climate as Predictors of Individual Innovation at Work'. Applied Psychology, 44, 199-215.

Burgelman, R. A. and Grove, A. S. (1996). 'Strategic dissonance'. California Management Review, 32, 8-28.

Chadwick, C. and Dabu, A. (2009). 'Human resources, human resource management, and the competitive advantage of firms: Toward a more comprehensive model of causal linkages'. Organization Science, 20, 253-272.

Chell, E. and Athayde, R. (2009). The Identification and Measurement of Innovative Characteristics of Young People: Development of the Youth Innovation Skills Measurement Tools. London: National Foundation for Science, Technology and the Arts (NESTA).

Choi, J. N. (2007). 'Change-oriented organizational citizenship behaviour: Effects of work environment characteristics and intervening psychological processes'. Journal of Organizational Behaviour, 28, 467-484.

Csikszentmihalyi, M. (1992). 'Motivation and creativity', in Albert, R.S. (Eds), Genius and Eminence. Oxford: Pergamon Press.

Curral, L. A., Forrester, R. H., Dawson, J. F. and West, M. A. (2001). 'It's what you do and the way that you do it: Team task, team size, and innovation-related group processes'. European Journal of Work Organizational Psychology, 10, 187-204.

Damanpour, F. (1988). 'Innovation type, radicalness, and the adoption process'. Communication Research, 15, 545-567.

Deci, E. L. and Ryan, R. M. (1985). Intrinsic Motivation and Self-determination in Human Behaviour. New York: Plenum Press.

Delbridge, R. and Whitfield, K. (2001). 'Employee perceptions of job influence and organizational participation'. Industrial Relations, 40, 472-489.

De Vaus, D. (2002). Surveys in Social Research. London: Routledge.

Dunn, D. S. (2009). Research Methods for Social Psychology. Hoboken, NJ: John Wiley \& Sons Ltd. 
Edmondson, A. C., Roberto, M. A. and Watkins, M. D. (2003). 'A dynamic model of top management team effectiveness: managing unstructured task streams'. The Leadership Quarterly, 14, 297-325.

Ehrnberg, E. (1995). 'On the definition and measurement of technological discontinuities'. Technovation, 15, 437-452.

Enkel, E., Gassmann, O. and Chesbrough, $\mathrm{H}$. (2009). 'Open R\&D and open innovation: exploring the phenomenon'. $R \& D$ Management, 39, 311-316.

Fayol, H. (1949). General and Industrial Management. London: Pitman.

Feist, G. J. (1998). 'A meta-analysis of personality in scientific and artistic creativity'. Personality and Social Psychology Bulletin, 2, 290-309.

Field, A. (2009). Discovering Statistics Using SPSS. London: Sage Publications.

Furnham, A. (2005). The Psychology of Behaviour at Work: The Individual in the Organization. New York: Psychology Press.

Furnham, A., Crump, J., Batey, M. and ChamorroPremuzik, T. (2009). 'Personality and ability predictors of the "consequences" test of divergent thinking in a large nonstudent sample'. Personality and Individual Differences, 46, 536-540.

Gentry, W. A., Mondore, S. P., and Cox, B. D. (2007). 'A study of managerial derailment characteristics and personality references'. Journal of Management Development, 26, 857-873.

Gilson, L. L. (2008). 'Why be creative: A review of the practical outcomes associated with creativity at the individual, group, and organizational levels', in Zhou, J. and Shalley, C. E. (Eds), Handbook of Organizational Creativity. New York: Erlbaum.

Gilson, L. L. and Shalley, C. E. (2004). 'A little creativity goes a long way: An examination of teams' engagement in creative processes'. Journal of Management, 30, 453-470.

Glover, J. A., Ronning, R. R. and Reynolds, C. R. (1989). Handbook of Creativity. New York: Plenum Press.

Glynn, M. A. (1996). 'Innovative genius: A framework for relating individual and organizational intelligences to innovation'. Academy of Management Review, 21, 1081-1111.

Goodwin, C. J. (2009). Research in Psychology: Methods and Design. Hoboken, NJ: John Wiley \& Sons.

Gough, H. G. (1957). California Psychological Inventory Manual. Palo Alto, CA: Consulting Psychologists Press.
Halinen, A., Salmi, A. and Havila, V. (1999). 'From dyadic change to changing business networks: An analytical framework'. Journal of Management Studies, 36, 779-794.

Helson, R. (1996). 'In search of the creative personality'. Creativity Research Journal, 9, 295-306.

Hertzberg, F. (1964). 'The motivation-hygiene concept and problems of manpower'. Personal Administration, 27, 3-7.

Hirst, G., Van Knippenberg, D. and Zhou, J. (2009). 'A cross-level perspective on employee creativity: Goal orientation, team learning behaviour, and individual creativity'. Academy of Management Journal, 52, 280-293.

Hitt, M. A., Hoskisson, R. E. and Kim, H. (1997). 'International diversification: Effects on innovation and firm performance in productdiversified firms'. Academy of Management Journal, 40, 767-798.

Ho, V. T., Wong, S-S. and Lee, C. H. (2011). 'A Tale of Passion: Linking Job Passion and Cognitive Engagement to Employee Work Performance'. Journal of Management Studies, 48, 26-47.

Howell, J. M. and Boies, K. (2004). 'Champions of technological innovation: The influence of contextual knowledge, role orientation, idea generation, and idea promotion on champion emergence'. The Leadership Quarterly, 15, 123-143.

Isaksen, S. G. and Puccio G. J. (1988). 'Adaptationinnovation and the Torrance tests of creative thinking: The level-style issue revisited'. Psychological Reports, 63, 659-670.

Janssen, 0. (2003). 'Innovative behaviour and job involvement at the price of conflict and less satisfactory relations with co-workers'. Journal of Occupational and Organizational Psychology, 76, 347-364.

John, O. P., Naumann, L. P. and Soto, C. J. (2008). 'Paradigm shift to the integrative Big Five trait taxonomy: History, measurement, and conceptual issues', in John, O. P., Robins, R. W. and Pervin, L. A. (Eds), Handbook of Personality: Theory and Research. New York: Guilford Press.

John, O. P. and Naumann, L. P. (2010). 'Surviving two critiques by block? The resilient Big Five have emerged as the paradigm for personality trait psychology'. Psychological Inquiry, 21, 44-49.

Kanter, R. M. (1983). The Change Masters. London: Cox \& Wyman Ltd.

Katz, D. (1964). 'The motivational basis of organizational behaviour'. Behavioural Science, 9, 131-146.
Kline, P. (1999). The Handbook of Psychological Testing. London: Routledge.

Lan, X. (2007). 'Why does a consumer participate in the process of co-creation?: A study on consumer's creative motivation'. Acta Psychologica Sinica, 39, 343-354.

Langelaan, S., Bakker, A. B. van Doornen, L. J. P. and Schaufeli, W. B. (2006). 'Burnout and work engagement: Do individual differences make a difference?'. Personality and Individual Differences, 40, 521-532.

Latham, G. P. and Locke, E. A. (1979). 'Goal Setting - A motivational technique that works'. Organizational Dynamics, 8, 68-80.

LeGrand, H. E. (1990). Experimental Inquiries: Historical, Philosophical, and Social Studies of Experimentation in Science. Dordrecht: Kluwer Academic Publishers.

Leifer, R., O'Connor, G. C. and Rice, M. (2001). 'Implementing radical innovation in mature firms: The role of hubs'. Academy of Management Executive, 15, 102-113.

LePine, J. A. and Dyne, L. (2001). 'Voice and cooperative behaviour as contrasting forms of contextual performance: Individual employee sales and creativity'. Journal of Organizational Behaviour, 23, 57-74.

Lepper, M., Greene, D. and Nisbett, R. (1973). 'Undermining children's intrinsic interest with extrinsic rewards: A test of the "overjustification" hypothesis'. Journal of Personality and Social Psychology, 28, 129-137. Lichtenthaler, U. and Lichtenthaler, E. (2009).

'A capability-based framework for open innovation: Complementing absorptive capacity'. Journal of Management Studies, 46, $1315-1338$.

Low, M. B. and MacMillan, I. C. (1988). 'Entrepreneurship: Past research and future challenges'. Journal of Management, 14, 139-161.

Lubart, T. (2001). 'Models of the creative process: past, present and future'. Creativity Research Journal, 13, 295-308.

Luhmann, N. (1990). Essays on Self-reference. New York: Columbia University Press.

Martínez-Sánchez, A., Vela-Jiménez, M.-A., Pérez-Pérez, M. and de-Luis-Carnicer, P. (2011). 'The dynamics of labour flexibility: Relationships between employment type and innovativeness'. Journal of Management Studies, 48, 715-736.

Maslow, A. (1943). 'A theory of human motivation'. Psychological Review, 50, 370-396.

Marcati, A. (2008). 'The role of SME entrepreneurs' innovativeness and personality in the adoption of innovation. 
Research Policy, 37, 1579-1590.

McGuigan, F. (1978). Experimental Psychology: A Methodological Approach. Englewood Cliffs, NJ: Prentice-Hall.

MacKinnon, D. W. (1965). 'Personality and the realization of creative potential'. American Psychologist, 20, 273-281.

Milliken, F. J., Bartel, C. A. and Kurtzberg, T. R. (2003). 'Diversity and creativity in work groups: A dynamic perspective on the affective and cognitive processes that link diversity and performance', in Paulus, P. B. and Nijstad, B. A. (Eds), Group Creativity: Innovation through Collaboration. Oxford: Oxford University Press. Mintzberg, H. (2004). Managers, not MBAs: $A$ Hard Look at the Soft Practice of Managing and Management Development. San Francisco, CA: Berrett-Koehler.

Morgan, J. and Wang, R. (2010). 'Tournaments of ideas'. California Management Review, 52 , 77-90.

Morris, M. W., Larrick, R. P. and Su, S. K. (1999). 'Misperceiving negotiation counterparts: When situationally determined bargaining behaviours are attributed to personality traits'. Journal of Personality and Social Psychology, 77, 52-67.

Moscovici, S. and Zavalloni, M. (1969). 'The group as a polarizer of attributes'. Journal of Personality and Social Psychology, 12, 125-135.

Mumford, M. D. (2000). 'Managing creative people: strategies and tactics for innovation'. Human Resource Management Review, 10, 313-351.

Mumford, M. D. and Gustafson, S. (1988). 'Creativity syndrome: Integration, application, and innovation'. Psychological Bulletin, 103, 27-43.

Newton, N. (1996). Foundations of Understanding (Advances in Consciousness Research). Amsterdam: John Benjamins.

Nishii, L. H. and Goncalo, J. A. (2008). 'Demographic faultlines and creativity in diverse groups', in Phillips, K. W., Mannix, E. A. and Neale, M. A. (Eds), Research on Managing Groups and Teams. Greenwich, CT: JAI Press.

Oldham, G. R. and Cummings, A. (1996). 'Employee creativity: Personal and contextual factors at work'. Academy of Management Journal, 39, 607-634.

Organ, D. W. and Konovsky, M. A. (1989). 'Cognitive versus affective determinants of organizational citizenship behaviour'. Journal of Applied Psychology, 74, 157-164.

Payne, G. T., Benson, G. S. and Finegold, D. L. (2009). 'Corporate board attributes, team effectiveness and financial performance'.
Journal of Management Studies, 46, 704-731.

Podsakoff, P. M., MacKenzie, S. B., Paine, J. B. and Bachrach, D. G. (2000). 'Organizational Citizenship Behaviours: A critical review of the theoretical and empirical literature and suggestions for future research'. Journal of Management, 26, 513-563.

Quinn, J. B. (1985). 'Managing innovation: Controlled chaos'. Harvard Business Review, $63,73-84$.

Ramachandran, V. S. (1994). Encyclopedia of Human Behaviour. San Diego, CA: Academic Press.

Rauch, A. and Frese, M. (2007). 'Let's put the person back into entrepreneurship research: A meta-analysis on the relationship between business owners' personality traits, business creation and success'. European Journal of Work and Organizational Psychology, 16, 353-385.

Rice, M. P., Kelley, D., Peters, L. and O'Connor, G. C. (2001). 'Radical innovation: Triggering initiation of opportunity recognition and evaluation'. R\&D Management, 31, 409-420.

Roffe, I. (1999). 'Innovation and creativity in organisations: A review of the implications for training and development'. Journal of European Industrial Training, 23, 224-241.

Scott, S. G. and Bruce, R. A. (1994). 'Determinants of innovative behaviour: A path model of individual innovation in the workplace'. Academy of Management Journal, 37, 580-607.

Segars, A. H. and Hendrickson, A. R. (2000). 'Value, knowledge, and the human equation: Evolution of the information technology function in modern organizations'. Journal of Labor Research, 21, 431-445.

Shalley, C. E., Zhou, J. and Oldham, G. R. (2004). 'The effects of personal and contextual characteristics on creativity: Where should we go from here?'. Journal of Management, 30, 933-958.

Silverberg, G. (2002). 'The discrete charm of the bourgeoisie: Quantum and continuous perspectives on innovation and growth'. Research Policy, 31, 1275-1289.

Simon, H. A. (1955). 'A behavioural model of rational choice'. Quarterly Journal of Economics, 69, 99-118.

Smith, C. A., Organ, D. W. and Near, J. P. (1983). 'Organizational citizenship behaviour: Its nature and antecedents'. Journal of Applied Psychology, 68, 653-663.

Snell, S. A. and Dean Jr. J. W. (1992). 'Integrated manufacturing and human resource management: $A$ human capital perspective'. Academy of Management Journal, 35, 467-504.
Sternberg, R. J. (1999). Handbook of Creativity. New York: Cambridge University Press.

Sternberg, R. J., O’Hara, L. A. and Lubart, T. I. (1997). 'Creativity as investment'. California Management Review, 40, 8-21.

Stüer, C., Hüsig, S. and Biala, S. (2010). 'Integrating art as a trans-boundary element in a radical innovation framework'. $R \& D$ Management, 40, 10-18.

Taggar, S. (2002). 'Individual creativity and group ability to utilize individual creative resources: A multilevel model'. Academy of Management Journal, 45, 315-330.

Taylor, F. W. (1917). The Principles of Scientific Management. New York: Harper.

Van de Ven, A. H., Polley, D. E., Garud, R. and Venkataraman, S. (2008). The Innovation Journey. New York: Oxford University Press.

Van Dijk, C. and Van den Ende, J. (2002). 'Suggestion systems: Transferring employee creativity into practical ideas'. $R \& D$ Management, 32, 387-395.

Weber, M. (1947). The Theory of Social and Economic Organizations. New York: Oxford University Press.

Weisberg, R. W. (1999). 'Creativity and knowledge: A challenge to theories', in Sternberg, R. J. (Eds), Handbook of Creativity. Cambridge: Cambridge University Press.

West, M. A. (2001). 'Creativity and innovation in organizations, management of', in Smelser, $\mathrm{N}$. and Baltes, P. (Eds), International Encyclopedia of the Social and Behavioural Sciences. Oxford: Pergamon Press.

Woodman, R. W., Sawyer, J. D. and Griffin. R.W. (1993). 'Toward a theory of organizational creativity'. Academy of Management Review, 18, 293-321.

Zahra, S., Yavuz, R. I. and Ucbasaran, D. (2006). 'How much do you trust me? The dark side of relational trust in new business creation in established companies'. Entrepreneurship Theory and Practice, 30, 541-559.

Zhang, X. and Bartol, K. M. (2010). 'The influence of creative process engagement on employee creative performance and overall job performance: A curvilinear assessment'. Journal of Applied Psychology, 95, 862-873.

Zhou, J. 2003. 'When the presence of creative coworkers is related to creativity: Role of supervisor close monitoring, developmental feedback, and creative personality'. Journal of Applied Psychology, 88, 413-422.

Zhou, J., and George, J. M. (2003). 'Awakening employee creativity: The role of leader emotional intelligence'. Leadership Quarterly, 14, 545-568. 